\title{
Can the substrate of the diamond anodes influence on
}

\section{the performance of the electrosynthesis of oxidants?}

\author{
Inmaculada Moraleda ${ }^{1}$, Salvador Cotillas $^{2}$, Javier Llanos ${ }^{1}$, Cristina Sáez ${ }^{1}$, Pablo \\ Cañizares $^{1}$, Laurent Pupunat $^{3}$, Manuel A. Rodrigo ${ }^{1 *}$ \\ ${ }^{1}$ Chemical Engineering Department, Faculty of Chemical Sciences and Technologies, \\ University of Castilla-La Mancha, Edificio Enrique Costa Novella. Campus \\ Universitario s/n, 13005 Ciudad Real, Spain \\ ${ }^{2}$ Chemical Engineering Department, School of Industrial Engineering \\ University of Castilla-La Mancha. Campus Universitario s/n, 02071 Albacete, Spain \\ ${ }^{3}$ Adamant Technologies, La Chaux de Fonds, Switzerland
}

\begin{abstract}
This work is focused on the evaluation of the performance of bulk electrosynthesis of chlorine oxoanions and peroxodisulfate with diamond electrodes, made with the same conductive-diamond coating deposited on three different substrates (niobium, tantalum and silicon). Results point out an important influence of the substrate on the efficiency of the processes. The diamond coatings on tantalum substrate leads to higher concentrations of hypochlorite and perchlorate from the electrolysis of synthetic brines. Specifically, the most remarkable influence has been observed at $1500 \mathrm{~A} \mathrm{~m}^{-2}$. This can be attributed to a production of large amounts of hydroxyl radicals which significantly contribute to the generation of hypochlorite and perchlorate by mediated oxidation of chloride and hypochlorite, respectively. On the contrary, the electrochemical production of peroxodisulfate is favored when using silicon as diamond substrate, as well at current densities higher than $1000 \mathrm{~A} \mathrm{~m}^{-2}$. Although the formation of peroxodisulfate depends on the production of hydroxyl radicals, this better performance of silicon (and even niobium)
\end{abstract}


can be related to the decomposition of peroxodisulfate by means of its reaction with the excessively high concentrations of hydroxyl radicals produced with diamond coatings deposited on tantalum. These results are of extreme significance for the tailoring of electrodes for specific applications, because they demonstrate that the boron doping and the $\mathrm{sp}^{3} / \mathrm{sp}^{2}$ ratios are not the only inputs to be considered.

Keywords: electrosynthesis; diamond; substrate; perchlorate; persulfate

*Corresponding author e-mail: manuel.rodrigo@uclm.es. Tel.: +34-926-29-53-00 Ext. 3411; fax: +34-926-29-52-56

\section{Highlights}

- Electrolysis with BDD anodes allows to generate powerful oxidants.

- Ta-BDD favors the generation of larger amounts of $\cdot \mathrm{OH}$ than Si-BDD or $\mathrm{Nb}$ BDD.

- Hypochlorite and perchlorates are more efficiently produced with Ta-BDD electrodes by mediated oxidation.

- Higher efficiencies for peroxodisulfate production with Si-BDD, because of its increased decomposition during Ta-BDD electrolysis.

\section{Introduction.}


In last decades, diamond based coatings have been evaluated as electrode material for the degradation of a wide variety of organic pollutants contained in wastewater, such as pharmaceuticals, dyes, pesticides, characterized for being difficult to be removed by conventional treatment technologies [1-6]. This material has a wide electrochemical window that favors the production of large amounts of free hydroxyl radicals during water electrolysis (Eq. 1) [7], which are known to be extremely efficient oxidants, and the responsible to consider electrolysis with diamond electrodes as an Advanced Oxidation Process (AOP).

$$
\mathrm{H}_{2} \mathrm{O} \rightarrow \cdot \mathrm{OH}+\mathrm{H}^{+}+\mathrm{e}^{-}
$$

In fact, this species is the main responsible for organic matter depletion, either directly or by side reactions [8-11]. Thus, hydroxyl radicals are known to interact between them to form hydrogen peroxide and ozone and to react with other ions contained in wastewater, favoring the production of other powerful oxidants, like hypochlorite and peroxoanions (e.g. peroxodiphosphate, peroxodisulfate and peroxocarbonate). These last ones are more stable (longer lifetime) than hydroxyl radical and allow the further oxidation of organics during the electrolysis of wastewater. In those processes, current density is a key parameter to control the amount of oxidants produced and temperature to preserve them once formed $[12,13]$. Sometimes, the species produced are less reactive at room temperature than the parent compound. This happens with the chlorite, chlorate and perchlorate formed by sequential oxidation of hypochlorite, whose formation is known to be one of the main drawbacks of the diamond environmental electrolytic technology [14]. However, what becomes a problem for water treatment is an opportunity for electrosynthesis, as currently the production of perchlorate is one of the most studied processes because of the large number of applications of this compound.

In this sense, most of the oxidants formed accidentally during water electrolysis can be suitable reagents for different applications such as bleaching [12], disinfection [15-17], 
pyrotechnics [18], detergents, organic synthesis [19, 20] and many more. However, they are difficult to be produced by other conventional technologies and, hence, electrolysis with diamond anodes can be a promising technology for their generation, becoming a potential market for these processes.

In the search of efficient electrosynthesis processes many works have evaluated the influence of the main characteristics of the diamond coatings on the efficiency of the process. In this context, Brito et al. have reported the electrosynthesis of active chlorine species using diamond anodes with different $\mathrm{sp}^{3} / \mathrm{sp}^{2}$ ratio, finding a remarkable influence of this parameter on the production of perchlorate: high graphite content leads to a higher production of this compound [21]. Likewise, De Paiva Barreto et al. evaluated the influence of $\mathrm{sp}^{3} / \mathrm{sp}^{2}$ ratio on the production of peroxodisulfate [22]. They concluded that lower $\mathrm{sp}^{3} / \mathrm{sp}^{2}$ ratios favor the electrochemical production of peroxodisulfate at higher current densities. Based on these previous works, diamond characteristics seem to remarkable affect the electrochemical production of powerful oxidants.

Within this frame, our research group evaluated the influence of boron content, the thickness and the $\mathrm{sp}^{3} / \mathrm{sp}^{2}$ ratio on the electrochemical production of peroxodiphosphate with commercial diamond anodes [23]. In that study, it was found that the most important parameter on the electrosynthesis of this oxidant was, surprisingly, the thickness of the diamond layer. Specifically, higher efficiencies were obtained when the electrode with the thinner layer was used. This result indicated that the substrate may have an important influence on the process performance, although in that moment we did not own reliable electrodes (electrodes with exactly the same characteristics made on different substrates) to check this hypothesis.

As it is well-known, Conductive Diamond coatings can be manufactured on different substrates such as silicon, niobium or tantalum. Most of papers reported in literature describes the use of diamond anodes for the electrosynthesis of oxidants with silicon 
substrate [24-26] and, to the authors' knowledge, the influence of the diamond substrate has not been evaluated for the electrochemical generation of powerful oxidants.

With this background, this work focuses on the evaluation of the performance of diamond coatings on the production of chlorine oxoanions and peroxodisulfate, trying to complement the results of our previous work, in order to verify if the substrate is an important input for predicting the performance of the oxidation process. Likewise, the behavior of different substrates is not only important for the technical viability of electrosynthesis of oxidants but also for the economical aspects since the price of tantalum is higher than niobium. Hence, diamond substrate is expected to be an important point to take into account in the economical viability of electrochemical processes.

\section{Material and methods.}

\subsection{Analytical procedures.}

Chlorine species were measured by ion chromatography using a Metrohm 930 Compact IC Flex coupled to a conductivity detector. A Metrosep A Supp 7 column was used to determine the concentration of chloride, chlorate and perchlorate. The mobile phase consisted of $85: 15 \mathrm{v} / \mathrm{v} 3.6 \mathrm{mM} \mathrm{Na}_{2} \mathrm{CO}_{3} /$ acetone solution with a flowrate of $0.80 \mathrm{~cm}^{3} \mathrm{~min}^{-}$

1. The temperature of the oven was $45^{\circ} \mathrm{C}$ and the volume injection was $20 \mu \mathrm{L}$. The peak of hypochlorite interferes with chloride in the chromatographic system used. For this reason, the concentration of hypochlorite was determined by a selective titration using $\mathrm{As}_{2} \mathrm{O}_{3}$ in $\mathrm{NaOH} 2 \mathrm{M}[27,28]$. Peroxodisulfate concentration was measured iodometrically according to Kolthoff \& Carr [29] and by UV spectrophotometry [30].

\subsection{Electrochemical cell.}

Electrolyses were carried out in a single-compartment electrochemical flow cell equipped with boron doped diamond (BDD) plates as electrodes (Adamant Technologies, 
Switzerland). The geometric area was $78 \mathrm{~cm}^{2}$ and, the interelectrode gap between the electrodes was $5 \mathrm{~mm}$. The electrodes were made on purpose for this work. The boron content of the electrodes was $2500 \mathrm{ppm}$. The $\mathrm{sp}^{3} / \mathrm{sp}^{2}$ ratio was not possible to evaluate due to the high level of boron doping. This favors Fano effect which alters Raman scattering of diamond lattice. Niobium, silicon and tantalum were used as substrates to deposit the diamond coating and the thickness of this coating was 7.8, 5.9 and 7.3 $\mu \mathrm{m}$, respectively.

\subsection{Experimental procedure.}

Bench scale electrolyses were carried out under galvanostatic conditions and batch operation mode. Synthetic brines $(\mathrm{NaCl} 1 \mathrm{M})$ or sulfate concentrate effluents $\left(\mathrm{H}_{2} \mathrm{SO}_{4} 1\right.$ M) were stored in a glass tank $\left(1 \mathrm{dm}^{3}\right)$ and circulated through the electrochemical cell by a peristaltic pump. A Delta Electronika ES030-10 power supply (0-30V, 0-10A) provided the electric current and, the applied current densities were within the range 300-1500 A $\mathrm{m}^{-2}$. A heat exchanger was used to maintain the temperature at $25^{\circ} \mathrm{C}$.

\section{Results and discussion.}

Electrolysis of chloride. Figure 1 shows the changes in the conversion of chloride to hypochlorite with the electric charge applied, during the electrolysis at four current densities $\left(300,600,1000\right.$ and $\left.1500 \mathrm{~A} \mathrm{~m}^{-2}\right)$ of synthetic brines $(1 \mathrm{M} \mathrm{NaCl})$ using diamond anodes made with the three different substrates: $\mathrm{Nb}$, Ta and $\mathrm{Si}$. 

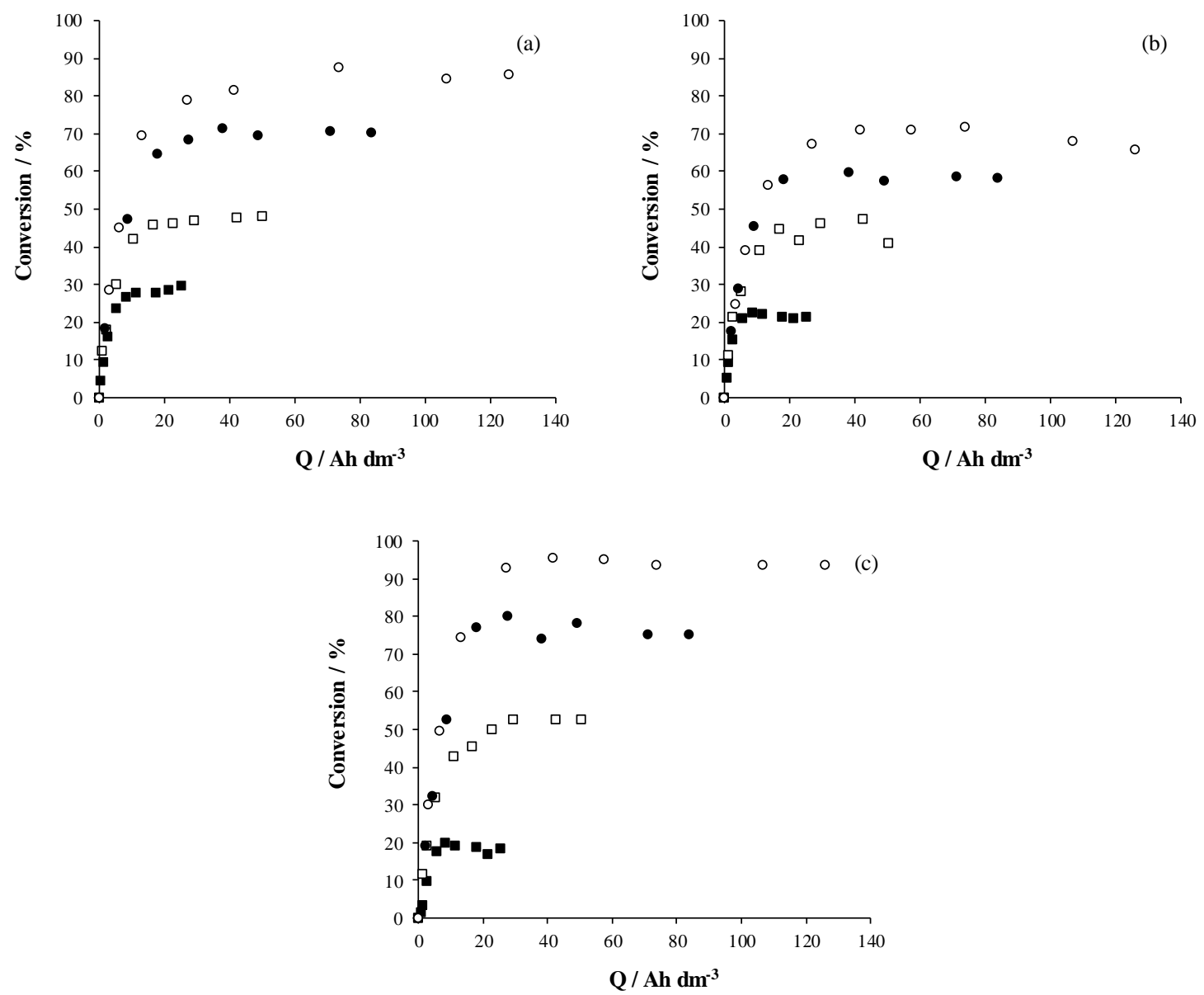

Figure 1. Hypochlorite conversion as function of the applied electric charge during the electrolysis of synthetic brines. Diamond substrate: (a) Nb; (b) Si; (c) Ta. Current density: (匹) $300 \mathrm{~A} \mathrm{~m}^{-2}$; (口) $600 \mathrm{~A} \mathrm{~m}^{-2}$; (•) $1000 \mathrm{~A} \mathrm{~m}^{-2}$; ( ( ) $1500 \mathrm{~A} \mathrm{~m}^{-2} \cdot \mathrm{C}_{0}: 1 \mathrm{M} \mathrm{NaCl}$.

As expected, hypochlorite conversion increases with the applied electric charge for all the tests carried out [31]. This increase is very fast during the first steps and then, it is followed by a plateau zone that corresponds to the maximum conversion achieved (in some cases there is not plateau but a decrease in the conversion at large current charge passed). The total conversion of chloride into hypochlorite is not reached in any of the tests, which suggests that an equilibrium between the rates of production and destruction of hypochlorite is reached during the electrolysis operated in discontinuous mode. Hypochlorite is known to be produced by disproportionation of the electrochemically formed chlorine (Eqs. 2-4) or by the action of hydroxyl radicals on chloride ions (Eq. 5). 


$$
\begin{gathered}
2 \mathrm{Cl}^{-} \rightarrow \mathrm{Cl}_{2}+2 \mathrm{e}^{-} \\
\mathrm{Cl}_{2}+\mathrm{H}_{2} \mathrm{O} \rightarrow \mathrm{HClO}+\mathrm{Cl}^{-}+\mathrm{H}^{+} \\
\mathrm{HClO} \rightleftharpoons \mathrm{H}^{+}+\mathrm{ClO}^{-} \\
\mathrm{Cl}^{-}+\cdot \mathrm{OH} \rightarrow \mathrm{ClO}^{-}+\mathrm{H}^{+}+\mathrm{e}^{-}
\end{gathered}
$$

At this point, it is worth to remember that with diamond electrodes the final product in the oxidation of chlorides is not hypochlorite but perchlorate [32]. Although there are chemical paths that explain the formation of chlorate by disproportionation and even by direct oxidation, the most important mechanism to explain this formation is by the action of hydroxyl radicals. In fact, in electrolysis with metal mixed oxide (MMO) anodes the amounts of chlorates formed are not very important at the operation conditions used in this work and, in addition, no perchlorates can be detected during the electrolysis with those electrodes [31].

Likewise, in the experiments carried out in this work, a very large concentration of chloride is used in the raw matter fed to the discontinuous electrochemical system and because of that, hypochlorite shows a pseudo-behavior of final product as the oxidation of chlorides by hydroxyl radicals will be easier than the oxidation of the hypochlorite.

Furthermore, results show that the electrochemical production of hypochlorite is clearly influenced by the current density: higher current densities mean higher hypochlorite conversion for the same applied charge. This means a more efficient process, which can be easily explained by the more important role of the hydroxyl radicals at these harsh conditions, as it was explained in a previous work of our group [13]. In that research, it was shown that direct oxidation mechanisms are promoted when working at low current densities, while operating at higher values promotes the importance of the mediated mechanisms based on hydroxyl radicals. 
Regarding the diamond substrate, the maximum hypochlorite conversion achieved was obtained when using the electrode with tantalum (Ta) followed by niobium $(\mathrm{Nb})$ and, finally, the silicon $(\mathrm{Si})$ substrate. This behavior suggests that Ta-BDD anode may be promoting the generation of larger amounts of hydroxyl radicals during the electrosynthesis and, hence, it would be more suitable for the electrochemical production of powerful oxidants based on chlorine through mediated oxidation (Eq. 5). To illustrate this point, Figure 2 shows the final hypochlorite conversion as function of the diamond substrate at different current densities. These conversion values practically correspond to the maximum conversion achieved during the electrosynthesis.

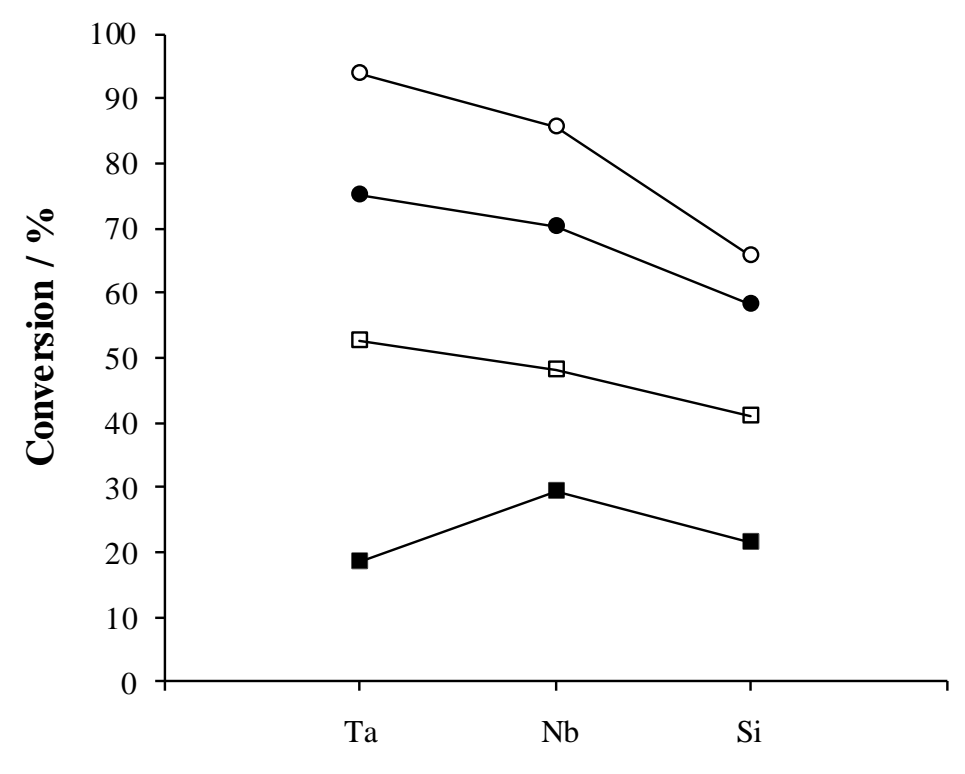

Diamond substrate

Figure 2. Final hypochlorite conversion as function of the diamond substrate during the electrolysis of synthetic brines. Current density. (ロ) $300 \mathrm{~A} \mathrm{~m}^{-2}$; (口) $600 \mathrm{~A} \mathrm{~m}^{-2}$; (•) 1000 $\mathrm{A} \mathrm{m}^{-2} ;(\circ) 1500 \mathrm{~A} \mathrm{~m}^{-2} \cdot \mathrm{C}_{0}: 1 \mathrm{M} \mathrm{NaCl}$.

Results clearly point out that the final conversion of chloride to hypochlorite is enhanced when using tantalum as the substrate of the diamond coating and when current densities higher than $600 \mathrm{~A} \mathrm{~m}^{-2}$ are applied. For example, it can be seen a higher conversion with this metal (Ta) during the electrosynthesis at $1000 \mathrm{~A} \mathrm{~m}^{-2}(75.21 \%)$ in comparison with 
the results obtained at $1500 \mathrm{~A} \mathrm{~m}^{-2}$ using silicon as substrate $(65.78 \%)$. On the other hand, the lowest conversion attained during the process at low current densities $\left(300 \mathrm{~A} \mathrm{~m}^{-2}\right)$ using Ta substrate can be related to a negligible production of hydroxyl radicals under these operating conditions and a less important direct oxidation process with this anode. Therefore, the experimental data obtained seem to confirm the excellent electrocatalytic properties of diamond anodes with tantalum substrate for the generation of large amounts of hydroxyl radicals at higher current densities. Likewise, it can be observed that the lowest conversion to hypochlorite is obtained during the electrosynthesis with Si-BDD, except for the case of $300 \mathrm{~A} \mathrm{~m}^{-2}$, for which direct oxidation mechanism is expected to control the process. This is a relevant result, since most of the papers reported in literature related to the application of diamond electrodes for wastewater treatment (removal of organics/disinfection) use this type of anodes with silicon substrate, almost as an standard electrode because of its supposed optimum behavior [2, 11, 33, 34]. Hence, the results obtained in this work open the possibility of improving the process efficiency by using Ta as substrate not only for the production of powerful oxidants based on chlorine but also for the treatment of wastewater, where the action of hydroxyl radicals is also expected to be very important.

As previously commented, the final trend observed in hypochlorite conversion (plateau zone) can be related to the oxidation of this compound to other species such as chlorate and perchlorate $[14,32]$, particularly to the moment in which the rates of production and destruction of this species are equalized. In this context, Figure 3 shows the conversion to chlorate during the electrolysis of the synthetic brines. 

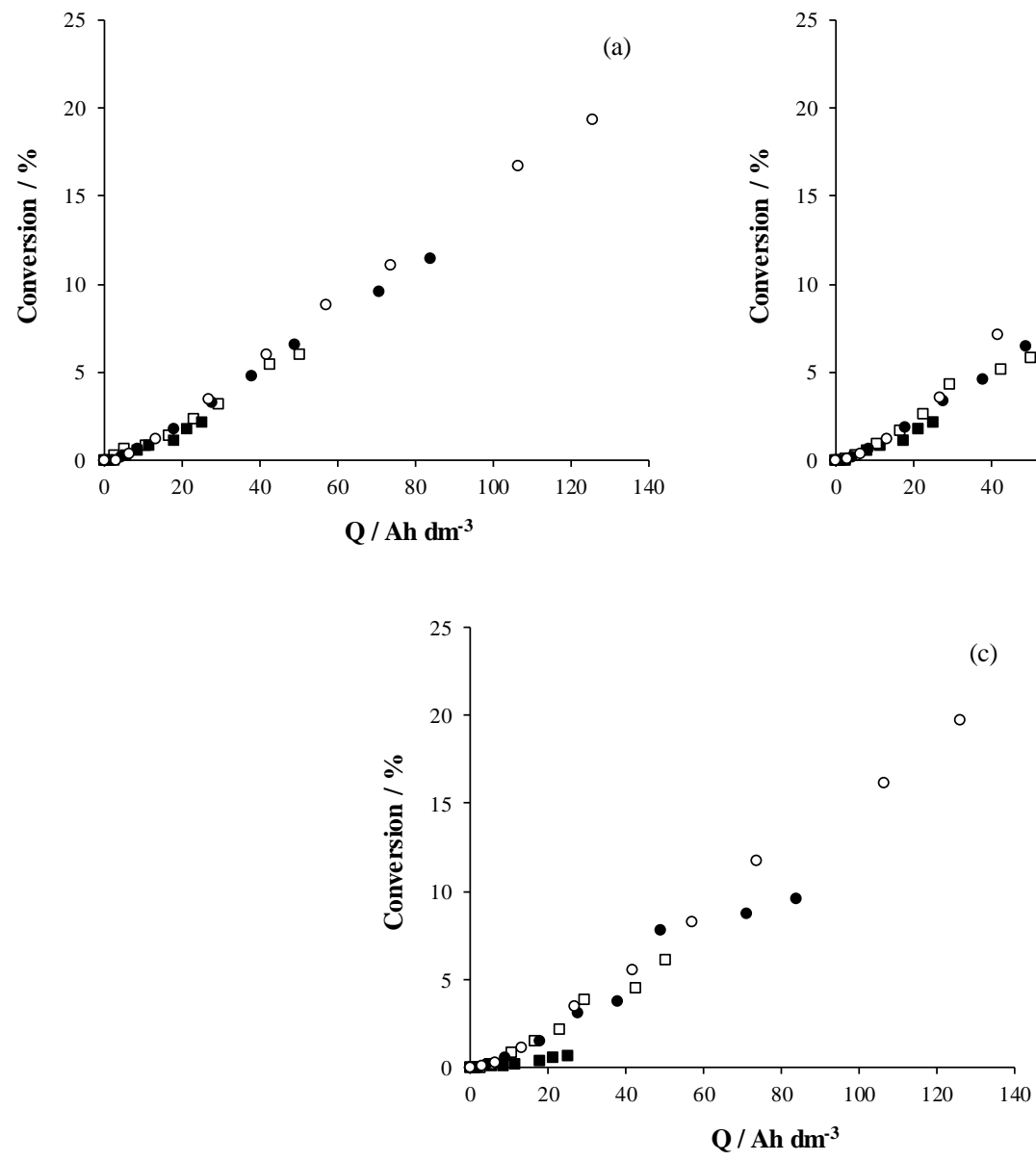

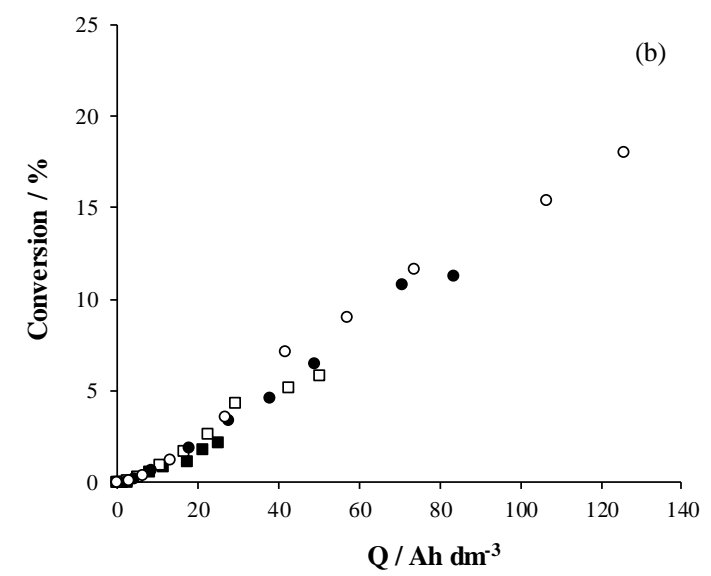

Figure 3. Chlorate conversion as function of the applied electric charge during the electrolysis of synthetic brines. Diamond substrate: (a) Nb; (b) Si; (c) Ta. Current density: (匹) $300 \mathrm{~A} \mathrm{~m}^{-2}$; () $600 \mathrm{~A} \mathrm{~m}^{-2}$; (•) $1000 \mathrm{~A} \mathrm{~m}^{-2}$; (०) $1500 \mathrm{~A} \mathrm{~m}^{-2} \cdot \mathrm{C}_{0}: 1 \mathrm{M} \mathrm{NaCl}$.

Chlorate conversion increases with the applied electric charge for all the tests carried out, regardless the diamond substrate used, and the current density applied. The experimental data follow a linear increase and, the maximum values that can be attained are lower than $25 \%$ for the highest current density $\left(1500 \mathrm{~A} \mathrm{~m}^{-2}\right)$ at electric charges around $130 \mathrm{Ah} \mathrm{dm}^{-}$ 3. Even so, the increasing trend observed suggests that the conversion could be significantly enhanced if larger electric charges are applied. In this case, there are not great differences as function of the diamond substrate since the chlorate conversion attained is low. In fact, if these results are compared to those obtained in the conversion to hypochlorite (Figure 1), the differences among the substrates appear from conversions 
higher than $20 \%$. Therefore, this seems to indicate that higher applied electric charges are required to observe a remarkable influence of the diamond substrate on the electrochemical production of chlorates because the concentration of hypochlorite is higher at these conditions and, this better ratio with respect to chloride increases their chances for being oxidized by hydroxyl radicals.

However, chlorate is only an intermediate in this process and the final product in the oxidation of chlorides with diamond anodes is perchlorate. Figure 4 shows the influence of the current density on the conversion to perchlorate during the tests carried out.
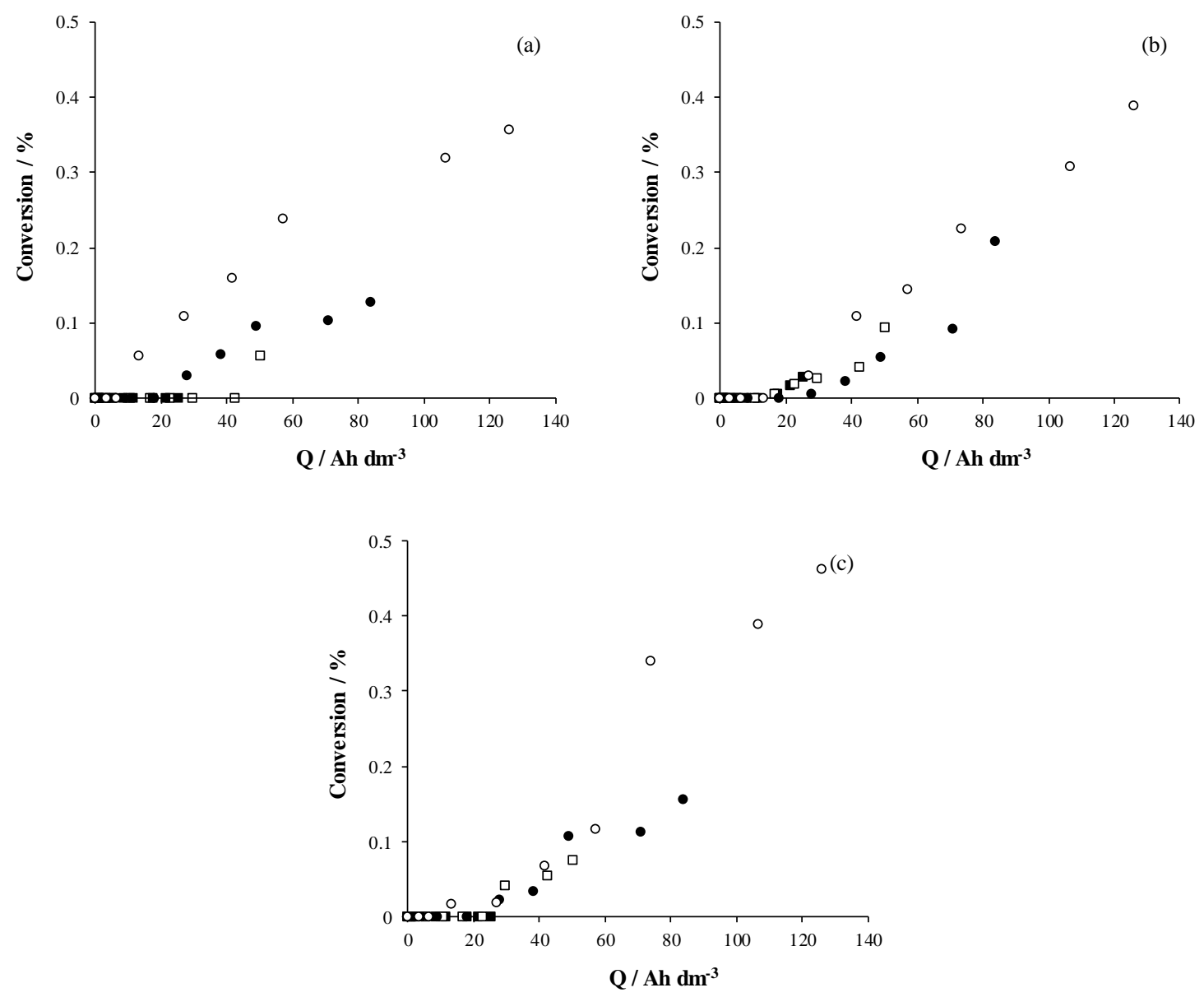

Figure 4. Perchlorate conversion as function of the applied electric charge during the electrolysis of synthetic brines. Diamond substrate: (a) Nb; (b) Si; (c) Ta. Current density: (匹) $300 \mathrm{~A} \mathrm{~m}^{-2}$; (口) $600 \mathrm{~A} \mathrm{~m}^{-2}$; (•) $1000 \mathrm{~A} \mathrm{~m}^{-2}$; (०) $1500 \mathrm{~A} \mathrm{~m}^{-2} \cdot \mathrm{C}_{0}: 1 \mathrm{M} \mathrm{NaCl}$. 
As it can be observed, the conversion to perchlorate increases with the applied electric charge during the process. However, the values obtained are very low $(<0.5 \%)$ due to extremely large amounts of free hydroxyl radicals that are required to convert all initial chlorides to perchlorate [12] and, the very important competition between chloride ions and chlorate ions, which is favored by the hugely higher concentration of the firsts. In this case, the diamond substrate does seem to influence the production of this species despite the low conversions achieved. Specifically, tantalum substrate leads to the highest conversion when working at higher current densities $\left(1500 \mathrm{~A} \mathrm{~m}^{-2}\right)$. These results agree the previous observed on hypochlorite conversion where this support (Ta) showed the best electrocatalytic properties to produce this oxidant (Figure 1). Again, this indicates that the contribution of hydroxyl radicals is more important with this electrode because the electrochemical production of perchlorate can only take place by the action of hydroxyl radicals [31]. For this reason, it is expected a higher conversion at $1500 \mathrm{~A} \mathrm{~m}^{-2}$ because the electro-generation of these radicals is favored under those conditions [7, 13].

To illustrate the influence of the diamond substrate on the production of perchlorates, Figure 5 summarizes the maximum amount electrogenerated of this oxidant and the efficiency during the electrolysis of synthetic brines with diamond anodes at $1500 \mathrm{~A} \mathrm{~m}^{-2}$.

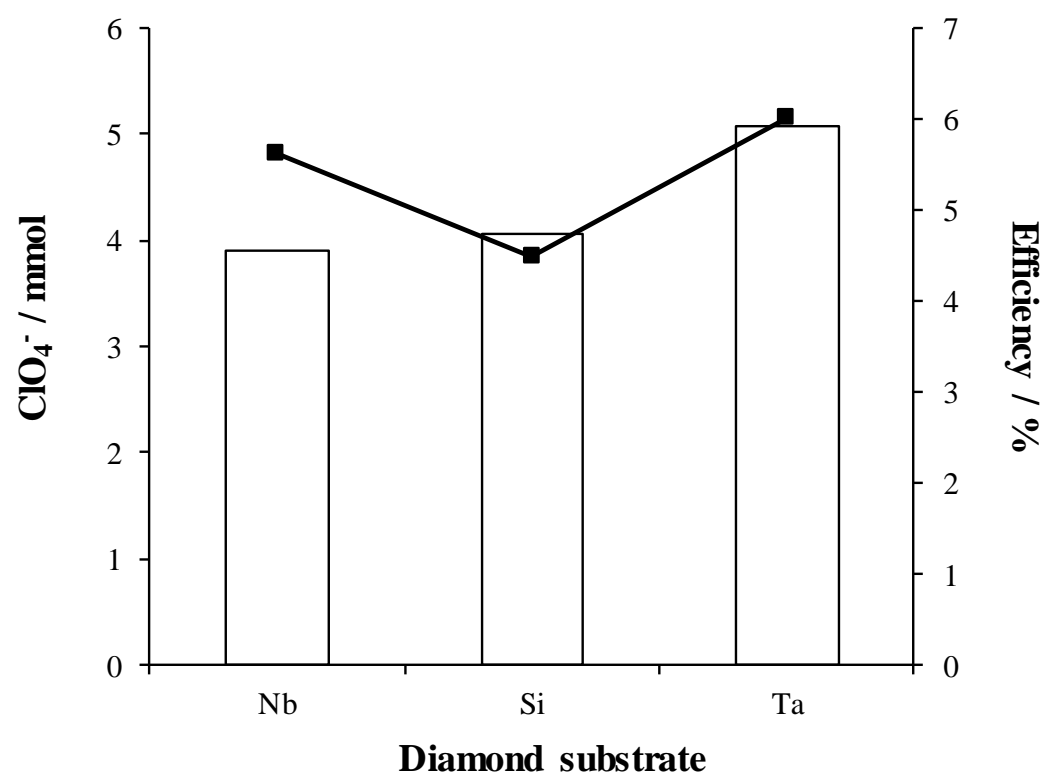


Figure 5. Maximum amount of electrogenerated perchlorate as function of the diamond substrate during the electrolysis of brines. $\mathrm{C}_{0}: 1 \mathrm{M} \mathrm{NaCl} ; \mathrm{j}: 1500 \mathrm{~A} \mathrm{~m}^{-2}$.

The maximum amount of perchlorate was obtained during the process with tantalum substrate followed by silicon and, finally, niobium. Nevertheless, the experimental data attained with niobium and silicon substrates were very similar ( $\mathrm{Nb}: 3.90 \mathrm{mmol} \mathrm{ClO}_{4}^{-}$; $\mathrm{Si}$ : $4.05 \mathrm{mmol} \mathrm{ClO}_{4}^{-}$). Therefore, these results clearly show the better electrocatalytic properties of Ta substrate for the production of perchlorates.

Regarding the efficiency, the highest value was obtained when working with tantalum as diamond substrate. Likewise, the efficiency during the process with niobium substrate was higher than that resulting in the process with silicon. This is an unexpected behavior taking into account that the concentration of perchlorate was a bit higher when silicon was used as substrate, but it is explained by the higher production of hypochlorite. Hence, the results obtained reveal that tantalum is the most appropriate support as diamond substrate for the electrosynthesis of oxidants based on chlorine whereas silicon substrate shows the lowest efficiency for electrochemical production of perchlorates.

Electrolysis of sulfates. Figure 6 shows the concentration of peroxodisulfate electrochemically generated as function of the applied electric charge during the electrolysis of concentrated sulfuric acid solutions $(1 \mathrm{M})$ at $1500 \mathrm{~A} \mathrm{~m}^{-2}$. 


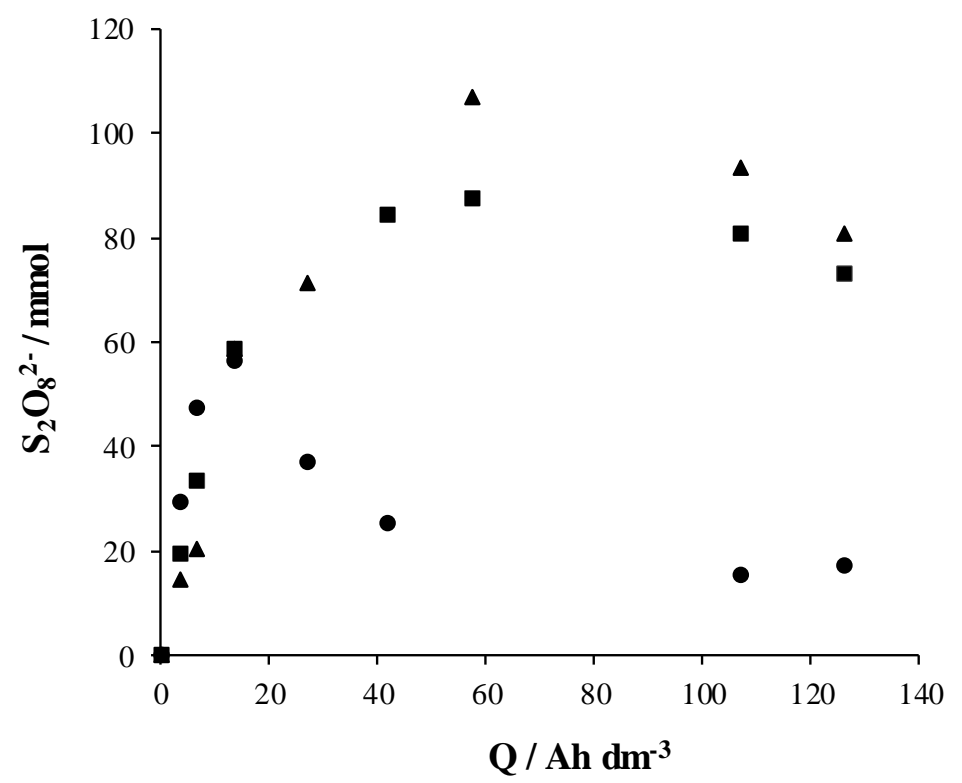

Figure 6. Concentration of electrogenerated oxidants as function of the applied electric charge during the electrolysis of synthetic solutions. Diamond substrate: ( $\mathbf{\square}) \mathrm{Nb}$; ( $\boldsymbol{\Delta}$ ) $\mathrm{Si}$; (•) Ta. Current density: $1500 \mathrm{~A} \mathrm{~m}^{-2} ; \mathrm{C}_{0}: 1 \mathrm{M} \mathrm{H}_{2} \mathrm{SO}_{4}$.

As can be observed, at the beginning of the electrolyses, the concentration of peroxodisulfate increases with the applied electric charge for all the tests carried out. Then, a maximum value is reached, from which the concentration starts to decrease. The formation of peroxodisulfate by direct oxidation is known to be very inefficient and its formation by mediated processes with hydroxyl radicals (Eq. 6) is the main mechanism that helps to explain the process [26]. Thus, with other electrodes, such as the MMO anodes, the production of peroxodisulfate during the electrolysis of sulfate solutions is reported to be almost negligible.

$$
2 \mathrm{SO}_{4}{ }^{2-}+\cdot \mathrm{OH} \rightarrow \mathrm{S}_{2} \mathrm{O}_{8}{ }^{2-}+\mathrm{OH}^{-}+\mathrm{e}^{-}
$$

As explained before, the flattening in the curve of electrolytic production of oxidants in discontinuous operation mode (or even the decrease) must be explained in terms of a competitive reaction for the destruction of the oxidant formed. Thus, this behavior can be related to peroxodisulfate decomposition by its reaction with hydroxyl radical, favoring 
the production of peroxodisulfate radicals (Eq. 7) [35]. Likewise, the electrogenerated hydrogen peroxide during electrosynthesis from the recombination of hydroxyl radicals (Eq. 8) can react with peroxodisulfate to produce free sulfate and hydroxyl radicals (Eq. 9) [36], which under the absence of other compounds to be oxidized, transform water into hydrogen peroxide and/or oxygen. This leads to a decrease in the efficiency of the process, although uncommonly, this decrease must be explained in terms of a higher production of hydroxyl radicals, clearly showing an antagonistic effect.

$$
\begin{gathered}
\mathrm{S}_{2} \mathrm{O}_{8}^{2-}+\cdot \mathrm{OH} \rightarrow \mathrm{S}_{2} \mathrm{O}_{8}{ }^{-}+\mathrm{OH}^{-} \\
\cdot \mathrm{OH}+\cdot \mathrm{OH} \rightarrow \mathrm{H}_{2} \mathrm{O}_{2} \\
\mathrm{~S}_{2} \mathrm{O}_{8}{ }^{2-}+\mathrm{H}_{2} \mathrm{O}_{2} \rightarrow 2 \mathrm{SO}_{4}^{-\cdot}+2 \cdot \mathrm{OH}
\end{gathered}
$$

Hence, an over-production of hydroxyl radicals can be negative from the point of view of production of sulfate and can help to explain the shape of the changes in the formation of peroxodisulfate during the discontinuous electrolyses.

On the other hand, in comparing electrodes, the production of peroxodisulfate is higher when working with silicon substrate followed by niobium and, finally, tantalum. These results are opposite to those observed during the electrosynthesis of oxidants based on chlorine, where tantalum showed the highest efficiency for the generation of these oxidants. However, these results are again indicating that diamond coatings deposited on tantalum are more efficient than the other two substrates in the production of hydroxyl radicals, although in this case, this enhanced production has a negative influence on the generation of the desired oxidant.

Figure 7 shows the final conversion to peroxodisulfate at different current densities when passing an electric charge of $25 \mathrm{Ah} \mathrm{dm}^{-3}$, arbitrary value selected to avoid the undesired side reaction that reduces the concentration of peroxodisulfate. 


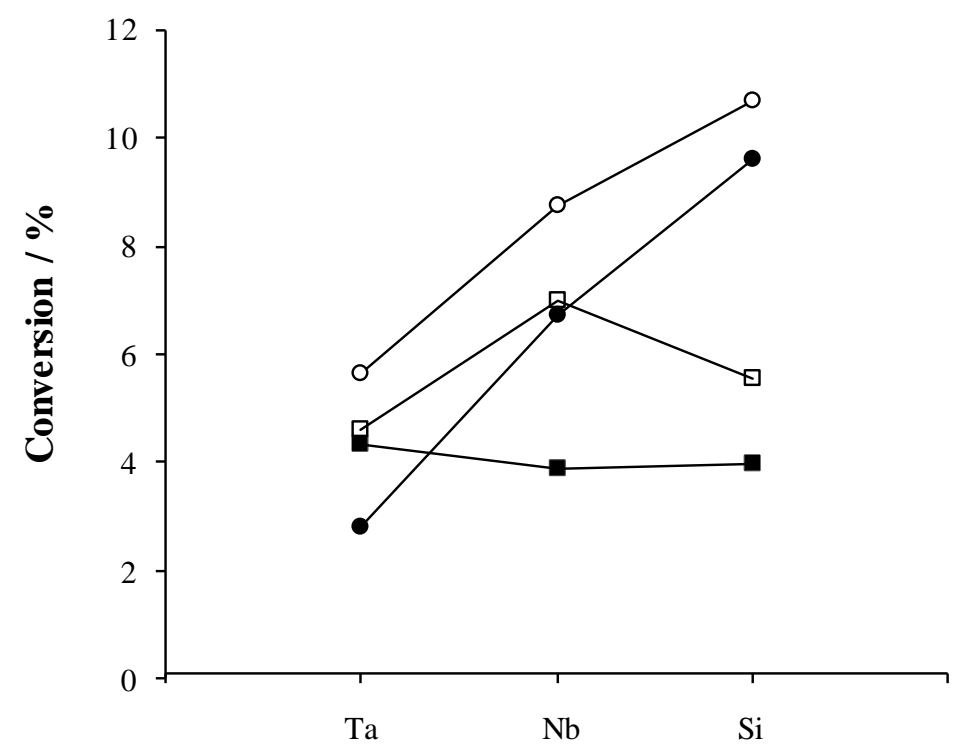

Diamond substrate

Figure 7. Final persulfate conversion as function of the diamond substrate during the electrolysis of synthetic solutions. (ロ) j: $300 \mathrm{~A} \mathrm{~m}^{-2}$; (口) j: $600 \mathrm{~A} \mathrm{~m}^{-2}$; (•) j: $1000 \mathrm{~A} \mathrm{~m}^{-2}$; (०) j: $1500 \mathrm{~A} \mathrm{~m}^{-2} \cdot \mathrm{C}_{0}: 1 \mathrm{M} \mathrm{H}_{2} \mathrm{SO}_{4}$.

The production of peroxodisulfate shows different behaviors depending on the range of current densities applied. Specifically, there are no important differences by operating at low current densities $\left(\mathrm{j}<500 \mathrm{~A} \mathrm{~m}^{-2}\right)$, region where the direct processes are supposed to control the overall rate. However, silicon substrate favors the production of large amounts of this oxidant when working at current densities higher than $1000 \mathrm{~A} \mathrm{~m}^{-2}$. These values $(\mathrm{j}$ $>1000 \mathrm{~A} \mathrm{~m}^{-2}$ ) have been reported in literature as the best operating conditions for the production of powerful oxidants by electrolysis with diamond anodes [24]. Hence, silicon substrate seems to be the most appropriate support for the electrosynthesis of peroxodisulfate whereas tantalum substrate shows the lowest efficiency for the generation of this oxidant with diamond anodes, although the explanation again is the higher production of hydroxyl radicals with this material. Niobium shows an intermediate behavior between tantalum and silicon, just similar to that observed in the electrolysis of chloride. 


\section{Conclusions.}

From this work, the following conclusions can be drawn:

- Electrolysis with diamond anodes allows to generate large amounts of powerful oxidants due to the excellent electrocatalytic properties of these electrodes for the electrochemical production of hydroxyl radicals at current densities higher than $1000 \mathrm{~A} \mathrm{~m}^{-2}$. These species significantly contribute to the oxidation of chlorides or sulfates, favoring the generation of chlorine-based oxidants or peroxodisulfates, respectively.

- Hypochlorite is the main oxidant species electrochemically produced during the electrolysis of synthetic brines at low electric charge passed. The use of current densities around $1500 \mathrm{~A} \mathrm{~m}^{-2}$ leads to the highest production of this oxidant, regardless the substrate tested. However, the maximum conversion towards this compound was obtained during the process using the diamond anode with tantalum substrate. This suggests that this support favors the electrochemical production of hydroxyl radicals and, therefore, the production of hypochlorite.

- Chlorate and perchlorate conversions are very low in comparison to the values obtained for hypochlorite because of the low electric current charge passed. The diamond substrate does not show a remarkable influence on the production of chlorate for all the current densities evaluated. However, in the case of perchlorate, tantalum substrate shows higher conversions to this compound than those obtained with silicon or niobium at current densities higher than $1000 \mathrm{~A} \mathrm{~m}^{-}$ ${ }^{2}$. These results can also be explained in terms of the higher production of hydroxyl radicals during the process with the Ta support.

- Silicon substrate is the most appropriate metal for the electrochemical production of persulfates with diamond anodes. This behavior is opposite to that observed on 
the production of oxidants based on chlorine and, it is related to the stability of the oxidant electrogenerated: persulfate can be decomposed by its reaction with hydroxyl radicals. Hence, tantalum substrate shows the worst efficiency for the production of this oxidant because of the excellent properties of this support for the production of large amounts of hydroxyl radicals.

\section{Acknowledgements}

Financial support from the Spanish Ministry of Economy, Industry and Competitiveness and European Union through project CTQ2017-91190-EXP (AEI/FEDER, UE) is gratefully acknowledged JCCM (Junta de Comunidades de Castilla-La Mancha) is also acknowledged for the postdoctoral grant (SBPLY/16/180501/000404) awarded to Dr. Salvador Cotillas.

\section{References}

[1] E. Brillas, C.A. Martínez-Huitle, Decontamination of wastewaters containing synthetic organic dyes by electrochemical methods. An updated review, Applied Catalysis B: Environmental 166-167 (2015) 603-643.

[2] C.A. Martínez-Huitle, M.A. Rodrigo, I. Sirés, O. Scialdone, Single and Coupled Electrochemical Processes and Reactors for the Abatement of Organic Water Pollutants: A Critical Review, Chemical Reviews 115(24) (2015) 13362-13407.

[3] M.A. Rodrigo, N. Oturan, M.A. Oturan, Electrochemically assisted remediation of pesticides in soils and water: a review, Chemical reviews 114(17) (2014) 8720-8745.

[4] S. Cotillas, E. Lacasa, C. Sáez, P. Cañizares, M.A. Rodrigo, Removal of pharmaceuticals from the urine of polymedicated patients: A first approach, Chemical Engineering Journal 331(Supplement C) (2018) 606-614. 
[5] C.A. Martínez-Huitle, M. Panizza, Electrochemical oxidation of organic pollutants for wastewater treatment, Curr. Opin. Electrochem. 11 (2018) 62-71.

[6] E. Lacasa, S. Cotillas, C. Saez, J. Lobato, P. Cañizares, M.A. Rodrigo, Environmental applications of electrochemical technology. What is needed to enable full-scale applications?, Curr. Opin. Electrochem. 16 (2019) 149-156.

[7] B. Marselli, J. Garcia-Gomez, P.A. Michaud, M.A. Rodrigo, C. Comninellis, Electrogeneration of hydroxyl radicals on boron-doped diamond electrodes, Journal of the Electrochemical Society 150(3) (2003) D79-D83.

[8] S. Cotillas, L. Cañizares, M. Muñoz, C. Sáez, P. Cañizares, M.A. Rodrigo, Is it really important the addition of salts for the electrolysis of soil washing effluents?, Electrochimica Acta 246 (2017) 372-379.

[9] Y. Lan, C. Coetsier, C. Causserand, K. Groenen Serrano, On the role of salts for the treatment of wastewaters containing pharmaceuticals by electrochemical oxidation using a boron doped diamond anode, Electrochimica Acta 231 (2017) 309-318.

[10] S. Cotillas, E. Lacasa, M. Herraiz, C. Sáez, P. Cañizares, M.A. Rodrigo, The Role of the Anode Material in Selective Penicillin G Oxidation in Urine, ChemElectroChem 6(5) (2019) 1376-1384.

[11] M. Panizza, G. Cerisola, Direct and mediated anodic oxidation of organic pollutants, Chemical Reviews 109(12) (2009) 6541-6569.

[12] A. Sánchez-Carretero, C. Sáez, P. Cañizares, M.A. Rodrigo, Production of Strong Oxidizing Substances with BDD Anodes, Synthetic Diamond Films: Preparation, Electrochemistry, Characterization, and Applications, John Wiley and Sons2011, pp. 281-310.

[13] P. Cañizares, C. Sáez, J. Lobato, R. Paz, M.A. Rodrigo, Effect of the operating conditions on the oxidation mechanisms in conductive-diamond electrolyses, Journal of the Electrochemical Society 154(3) (2007) E37-E44. 
[14] M.E.H. Bergmann, J. Rollin, T. Iourtchouk, The occurrence of perchlorate during drinking water electrolysis using BDD anodes, Electrochimica Acta 54(7) (2009) 21022107.

[15] H. Gallard, U. von Gunten, Chlorination of natural organic matter: kinetics of chlorination and of THM formation, Water Research 36(1) (2002) 65-74.

[16] L.V. Venczel, M. Arrowood, M. Hurd, M.D. Sobsey, Inactivation of Cryptosporidium parvum oocysts and Clostridium perfringens spores by a mixed-oxidant disinfectant and by free chlorine, APPL. ENVIRON. MICROBIOL. 63(4) (1997) 15981601.

[17] A. De Battisti, P. Formaglio, S. Ferro, M. Al Aukidy, P. Verlicchi, Electrochemical disinfection of groundwater for civil use - An example of an effective endogenous advanced oxidation process, Chemosphere 207 (2018) 101-109.

[18] K.L. Kosanke, R.C. Dujay, B.J. Kosanke, Pyrotechnic Reaction Residue Particle Analysis, Journal of Forensic Sciences 51(2) (2006) 296-302.

[19] J.A. Rosso, F.J. Rodríguez Nieto, M.C. Gonzalez, D.O. Mártire, Reactions of phosphate radicals with substituted benzenes, Journal of Photochemistry and Photobiology A: Chemistry 116(1) (1998) 21-25.

[20] J.A. Rosso, P. Caregnato, V.C. Mora, M.C. Gonzalez, D.O. Mártire, Reactions of Phosphate Radicals with Monosubstituted Benzenes. A Mechanistic Investigation, Helvetica Chimica Acta 86(7) (2003) 2509-2524.

[21] C.D.N. Brito, D.M. De Araújo, C.A. Martínez-Huitle, M.A. Rodrigo, Understanding active chlorine species production using boron doped diamond films with lower and higher sp3/sp2 ratio, Electrochemistry Communications 55 (2015) 34-38.

[22] J.P. De Paiva Barreto, K.C. De Freitas Aráujo, D.M. De Aráujo, C.A. MartínezHuitle, Effect of sp3/sp2 ratio on boron doped diamond films for producing persulfate, ECS Electrochemistry Letters 4(12) (2015) E9-E11. 
[23] P. Cañizares, C. Sáez, A. Sánchez-Carretero, M.A. Rodrigo, Influence of the characteristics of $\mathrm{p}-\mathrm{Si} \mathrm{BDD}$ anodes on the efficiency of peroxodiphosphate electrosynthesis process, Electrochemistry Communications 10(4) (2008) 602-606.

[24] P. Cañizares, C. Sáez, A. Sánchez-Carretero, M.A. Rodrigo, Synthesis of novel oxidants by electrochemical technology, Journal of Applied Electrochemistry 39(11) (2009) 2143-2149.

[25] S. Cotillas, A. Sánchez-Carretero, P. Cañizares, C. Sáez, M.A. Rodrigo, Electrochemical synthesis of peroxyacetic acid using conductive diamond electrodes, Industrial and Engineering Chemistry Research 50(18) (2011) 10889-10893.

[26] K. Serrano, P.A. Michaud, C. Comninellis, A. Savall, Electrochemical preparation of peroxodisulfuric acid using boron doped diamond thin film electrodes, Electrochimica Acta 48(4) (2002) 431-436.

[27] A.v. Wilpert, Über die Analyse von Hypochlorit und Chlorit in einer Lösung, Z. Anal. Chem. 155(5) (1957) 378-378.

[28] H. Freytag, Zur Bestimmung von Hypochlorit, Chlorid und Chlorat in Chlorkalk, Z. Anal. Chem. 171(6) (1959) 458-458.

[29] I.M. Kolthoff, E.M. Carr, Volumetric determination of persulfate in the presence of organic substances, Analytical Chemistry 25(2) (1953) 298-301.

[30] C. Liang, C.F. Huang, N. Mohanty, R.M. Kurakalva, A rapid spectrophotometric determination of persulfate anion in ISCO, Chemosphere 73(9) (2008) 1540-1543.

[31] A. Sánchez-Carretero, C. Sáez, P. Cañizares, M.A. Rodrigo, Electrochemical production of perchlorates using conductive diamond electrolyses, Chemical Engineering Journal 166(2) (2011) 710-714.

[32] M.E.H. Bergmann, Drinking water disinfection by in-line electrolysis: Product and inorganic by-product formation, Electrochemistry for the Environment, Springer New York2010, pp. 163-204. 
[33] S. Cotillas, E. Lacasa, C. Sáez, P. Cañizares, M.A. Rodrigo, Disinfection of urine by conductive-diamond electrochemical oxidation, Applied Catalysis B: Environmental 229 (2018) 63-70.

[34] H. Bergmann, A discussion on diamond electrodes for water disinfection electrolysis, Zur Bewertung von Diamantelektroden für die Wasserdesinfektionselektrolyse 151(6) (2010) 604-613.

[35] C. Liang, H.-W. Su, Identification of Sulfate and Hydroxyl Radicals in Thermally Activated Persulfate, Industrial \& Engineering Chemistry Research 48(11) (2009) 55585562.

[36] M.L. Crimi, J. Taylor, Experimental evaluation of catalyzed hydrogen peroxide and sodium persulfate for destruction of BTEX contaminants, Soil Sediment Contam. 16(1) (2007) 29-45. 